\title{
LA EDUCACIÓN EN EL TURISMO O EL TURISMO CON EDUCACIÓN ANTES DE LA PANDEMIA, DURANTE LA PANDEMIA Y POST PANDEMIA
}

\author{
Dr. Bernardo Muñoz Aguilar ${ }^{1}$
}

\begin{abstract}
Resumo:
Este artigo trata dos distintos tipos de turismo antes da pandemia do COVID19 e explica como deberá ser reformulado este numa nova era, quando o turismo será chamado para construir novas pontes em um novo mundo. Um turismo que demanda mais pelos visitantes e com maiores demandas por parte dos visitados e dos territórios que estarão sujeitos a tal demanda. O mundo necesita de um novo turismo, uma nova oferta com maior valor até as pessoas e a Pachamama e que essa indústria se torne realmente uma indústria limpa, de ócio recreativo, que responda às grandes somas de dinheiro que maneja a indústria internacional, somente abaixo da venda de armas e do que é proveniente do narcotráfico. ${ }^{2}$ A economia criativa, ou economia Naranja, representa uma riqueza baseada no talento, na propriedade intelectual, na conectividade e na cultura de nossa região para aproveitar melhor os capitais culturais que trazemos e é a base do turismo naranja, que o Dr. Jordi Tresserras Juan cria e que se explicita no corpo deste artigo. Em síntese, o COVID19 gera o colapso da indústria do turismo maciço e separado da Pachamama, tal qual se o conheceu. Bifurcação e salto quântico. Todo o sistema anterior já não existe mais. Na será normal.
\end{abstract}

Palavras-chave: Turismo sustentável. Pandemia e pós-pandemia. Turismo naranja. Ecologia profunda. América Latina. Construtos a partir do SUL.

\section{Resumen:}

El articulo recorre los distintos tipos de turismo antes de la pandemia del COVID19 y explica como deberá reformularse éste en una nueva era en donde el turismo está llamado a construir nuevos puentes en un nuevo mundo. Un turismo más demandante con los visitantes y con mayores demandas por parte de los visitados y de los territorios que serán sujetos de dicha demanda. Un nuevo turismo necesita el mundo, una nueva oferta con mayor valor hacia las personas y la Pachamama y que esta industria se torne realmente una industria limpia, de ocio creativo, que responda a las grandes sumas de dinero que maneja la industria internacional, sólo por bajo de las ventas de armas y de los provenientes del narcotráfico. ${ }^{3}$ La economía creativa, o economía Naranja, representa una riqueza basada en el talento, la propiedad intelectual, la conectividad, la cultura de nuestra región, para aprovechar mejor los capitales culturales que portamos y es la base del turismo naranja que crea el Dr. Jordi Tresserras Juan y que se explicita en el cuerpo de este artículo. En síntesis, el COVID19 genera el colapso de la industria del turismo masivo y separado de la Pachamama tal cual se le conoció. Bifurcación y salto cuántico. Todo el sistema anterior ya no existe más. Nada será normal.

Palabras clave: Turismo sostenible. Pandemia/Postpandemia. Turismo naranja. Ecología profunda. América Latina. Constructos desde el SUR.

\footnotetext{
${ }^{1}$ Antropólogo social. Investigador associado del CERU de la Universidad de São Paulo, Posdoctorante em la Universidad se Barcelona - Covenio SUR-SUR com el CERU y la Universidad de (Chile).

${ }^{2}$ La Economía Naranja. Una oportunidad infinita. Buitrago Restrepo, Pedro Felipe; Duque Márquez, Iván. 2013. Colombia.

Este artículo se termina de escribir con mis hij@s Antonia Luna y Simón Antai en el corazón. Desde el día 12 de marzo, día de mi cumpleaños, que nos los puedo abrazar, pues \#nosotrosnosquedamosencasa.

${ }^{3}$ La Economía Naranja. Una oportunidad infinita. Buitrago Restrepo, Pedro Felipe; Duque Márquez, Iván. 2013. Colombia.
} 


\begin{abstract}
:
This article reviews different types of tourism prevailing before the COVID-19 pandemic and explains how tourism has to be redefined in a new era in which it has to build new bridges in a new world. This new tourism will be more demanding for the visitors, as the visited populations and territories will establish new requirements. The world needs a new tourism, with a new supply with more value for the persons and the Pachamama. This industry has to become a really clean one, with creative leisure, which responds to the big sums of money this industry manages internationally, only smaller than the trade in arms and narcotics. The creative or orange economy represents treasures based on talents, intellectual property, connectivity and our region's culture. Our cultural capital can be taken advantage of as the foundation of the orange tourism defined by Dr. Jordi Tresserras Juan which is discussed in this article. Summing up, COVID-19 leads to the collapse of the massive tourism industry as we know it, and which is separated from Pachamama. Bifurcation and quantum leap. The whole of the previous system ceased to exist. Nothing will be normal.
\end{abstract}

Keywords: Sustainable tourism. Pandemic/Postpandemic. Orange tourism. Deep ecology. Latin America. Construct from the SOUTH.

\title{
Introducción
}

Agradezco también profundamente a Mia Brummer quien me ha enseñado la relevancia de la ecología profunda, no sólo en el turismo sostenible, sino que en todas las relaciones humanas.

Dicho lo anterior, planteamos que el turismo ha sido pieza clave en la educación para millones de personas, tanto para las que han tenido la posibilidad de viajar, como también para aquellas que han tenido la posibilidad de recibir y convivir con los viajeros. Asimismo, ha tenido un impacto inconmensurable en el devenir de quien acoge este ir y venir: la Pachamama.

¿Por qué, quién ha sufrido los embates de estos desplazamientos? Han sido los territorios culturales, la Pachamama, los destinos turísticos sostenibles, los cuales han sufrido tal asedio con dichos desplazamientos que se han quejado, han sufrido, lo que en términos del mundo del turismo se denomina sobrecarga turística.

A continuación, se desarrollará una suerte agenda de conceptos y actividades ligadas a la industria del turismo, que explican este acercamiento a través de la educación para el turismo hasta llegar a un turismo de ecología profunda, lo que sin dudas debería generar un impacto virtuoso en el turismo que se desarrolle tras la época de Pandemia.

1) Los viajes de descubrimientos

Estos, ya cercanos al objetivo de este artículo se enmarcan en los grandes viajes de los descubridores del occidente actual y más cercano aún los realizados hacia la actual América del Sur, caracterizados por los viajeros Cristóbal Colón, Fernando de Magallanes y Sebastián 
Cadernos CERU, Série 2, Vol. 31, n. 1, jun. 2020

Elcano. Estos viajeros establecieron las grandes rutas de las especias y de los esclavos, del dominio y subyugación de los pueblos indígenas y de sus lenguas y culturas.

\section{2) Los viajes masivos}

Podemos situarlos, con los desplazamientos hacia la América hispana "descubierta y conquistada", con los grandes procesos de viajes de colonos fundamentalmente españoles, italianos, alemanes, suizos, entre otras nacionalidades, ya en el siglo XVIII. Luego la América hispanizada se pobló de nuevas rutas las que antecedieron a las de siglo XIX francamente abriendo las rutas del turismo. Grandes y largos viajes en navíos consolidaron la fascinación de los europeos que vinieron a vernos. Pero muchos se quedaron. Las playas, los volcanes, el clima, los sabores, los habanos, la cadenciosa música y bellas mujeres y hombres acabaron por “conquistarlos a ellos". Y nació el mestizaje racial y cultural. Vinieron para quedarse en el dominio.

3) Los viajes All inclusive

En una versión inmediatamente postmoderna se instalaron en todas nuestras costas, o sea las costas de la Pachamama. También los All inclusive y grandes resorts. Con suntuosas instalaciones y infraestructura generaron el placer y el hedonismo del visitante para el cual todo estaba a disposición. Todo.

Un solo detalle marca el carácter de esos resorts. Muchos eran sólo para los viajeros extranjeros y a lo más, al nativo o nativa, sólo se permitía el ingreso para trabajar, divertir y servir. Había antes de la pandemia una barrera social, cultural y económica infranqueable.

4) La sobrecarga de los cielos

Ya en el siglo XX y XXI el avión vino a poner cercanía en los desplazamientos y a la curiosidad creciente que ya se ponía a disposición a un público más amplio y heterogéneo, lo cual incluyó también viajeros y viajeras selectas, que hicieron del destino América del Sur hispana un territorio de creación, de ocio y contemplación. Y muchos y muchas también se quedaron, produciendo con esto un círculo virtuoso inter y multicultural. Pero el espacio aéreo se llenó de estelas venenosas del queroseno que indefectiblemente además de surcar los cielos han generado un gran hoyo de ozono en la estratósfera, lo que era ya una tragedia.

5) La sobrecarga de la Pachamama

Indudablemente que esta sobrecarga de los cielos impactó directamente sobre nuestra y única Pachamama. La cual dijo basta y veremos eso en la parte del turismo en la post pandemia. 
No nos preguntábamos, o el turismo y los turistas no se preguntaban, donde y como se realizaba el turismo.

6) Dos ejemplos de sobrecarga turística: Acapulco y San Pedro de Atacama En las décadas de los 60 y 70s era de muy buena familia ir de vacaciones a Acapulco en México. Matrimonios, veraneos, ostentación, romances furtivos, todo se podía celebrar en Acapulco. Cuarenta años después el destino Acapulco ha colapsado y simplemente para la industria del turismo fue un capítulo. Hoy podríamos decir, o sea ayer, antes de la pandemia del CVID19, que su lugar lo ocupaba Punta Cana, en la República Dominicana.

En tanto, San Pedro de Atacama pasó de der un grupo de poblados en el desierto de Atacama, de agricultores y pastores reunidos bajo el concepto del ayllu, a ser uno de los principales destinos únicos de Chile para el mundo. Su riqueza arqueológica y los secretos que guardaba el desierto a partir de los descubrimientos de Gustavo Le Paige, otro viajero destacado. Sin embargo, luego de los viajeros descubridores, incluidos los tiawanaku, los incas, el Estado chileno y miles de viajeros de todo el mundo, el destino San Pedro antes de la pandemia era ya un destino con sobrecarga turística y además el pueblo Likanantai ya había perdido nuevamente el control de su territorio en cuanto a una propuesta de control de su patrimonio cultural, puesto en valor como una propuesta de turismo sostenible con altos estándares de calidad internacional con identidad.

Hoy los operadores turísticos afuerinos piden asistencia social para sobrevivir ante el nulo arribo de visitantes producto de la pandemia. En esta nueva situación, son naturalmente los Likanantai, quienes los están socorriendo justamente con productos de la Pachamama, de quienes estos operadores se habían desvinculado, para maximizar sus réditos con los viajeros que desaparecieron y que entre todos dejaron a la Pachamama muy herida.

7) El turismo respetuoso

Sin embargo, no podemos dejar de mencionar que también en los últimos 30 años, por fijar un tiempo y un tempo, se produjo un turismo respetuoso, es decir una harmonía entre los visitantes, los visitados y el territorio del destino turístico.

Además, aparecen los expertos en turismo, que comienzan a aconsejar sobre los destinos y a definir los distintos tipos de turismo que se desarrollaban y a aconsejar otras modalidades que se alejaban de la industria masiva y privilegiaban un turismo sostenible. Entonces aparecen el turismo vivencial, el turismo ecológico, el turismo del voluntariado, el turismo sexual, el 
Cadernos CERU, Série 2, Vol. 31, n. 1, jun. 2020

turismo naranja que plantea el Dr. Jordi Tresserras Juan ${ }^{4}$, una nueva y virtuosa forma de entender la visita turística.

8) El turismo ecológico

El turismo ecológico surgió de las preocupaciones verdes y de la necesidad de cuidar el medio ambiente por parte de los visitantes y los visitados. Al ver tanta maravilla como una reserva de la biosfera, afuerinos y lugareños implementaron modelos para cuidar el destino. Esto se desarrolló de un lado en términos altamente ligados a la ecología profunda, pero también se constituyó en un modelo de educación al permitir a niños, jóvenes y adultos el poder plantar un árbol y cuidarlo después desde su lugar de origen en términos virtuales. Otra modalidad se desarrolló en las Islas Galápagos, donde el visitante apadrinaba una tortuga y luego podía observar su desarrollo y comportamiento también en términos virtuales. Ambas modalidades pretendían contribuir a cuidar y mejorar las condiciones ecológicas del entorno que habían visitado y se educaban a través de este tipo de actividades.

9) El turismo social

En cierto sentido el turismo social también confrontaba al visitante con una realidad muy diferente a la suya por un periodo de tiempo acotado. De un lado podía visitar en un país o una ciudad a un barrio popular y compartir con sus habitantes una jornada, un fin de semana y conocer su día a día. Dormir en un hostal de buena calidad, limpio. Almorzar la comida típica en casa de una vecina o de una organización social, compartir una fiesta e intercambiar sus capitales sociales y culturales. Todo dependía de la calidad de la organización del tour operador cultural, de la oferta local y de los intereses del visitante para conseguir tender los puentes a través de este turismo.

\section{0) El turismo religioso}

En una época ex ante pandemia grandes multitudes se reunían para agasajar y adorar a una virgen, a un santo, en una gran mezcla de sincretismo religioso.

Antes de avanzar sobre este punto remitámonos a una actividad del turismo religioso que se instaló en el marco de la industria turística moderna en el Camino de San Santiago es la denominación que tienen una serie de rutas de peregrinación cristiana de origen medieval, que orientadas a combinar el turismo religioso con una ruta moderna generó diversas actividades asociadas con este camino que lo hicieron famoso en el mundo entero. Mañana deberemos observar cómo se recrea.

\footnotetext{
${ }^{4}$ https://www.hosteltur.com/comunidad/004289_el-turismo-naranja-el-color-del-turismo-cultural-y-creativorumbo-a-una-alianza-estrategica-entre-los-sectores-cultural-y-turistico.html
} 
Cadernos CERU, Série 2, Vol. 31, n. 1, jun. 2020

En este sentido y volviendo al Sur, y poniendo como ejemplo a las grandes aglomeraciones en el mundo Pan andino, días y noches de fiestas religiosas y paganas, asociadas a la Virgen del Carmen, a un Santo Patrono como San Pedro, eran rememoradas cada año, en este caso en el norte andino chileno. Un pueblo de la primera región de Chile, Tarapacá llamado La Tirana, justamente en honor a la Virgen de la Tirana, basó su mítico sincretismo en el amor prohibido entre un español y una ñusta local, que se saldó con la muerte de ambos, celebraban, hasta el año pasado, en una gran iglesia católica esa unión entre lo católico y lo prehispánico.

Esto en un pueblo con 800 habitantes durante el año y durante la semana que duraba la fiesta, se aglomeraban hasta 250.000 fieles. Un pueblo en medio del desierto y con oscilaciones térmicas que van desde los 30 grados durante el día hasta el frio del desierto nocturno con varios grados bajo cero.

De forma oficial se decretaba ley seca durante los días de la fiesta, pero contrario sensus, muchos fieles y feligresas caminaban y pasaban el frío y el calor bajo ingentes cuotas de alcohol.

Se contrataban las mejores bandas de bronce tanto de Bolivia como Perú, especialmente por parte de las diabladas, las cuales no escatimaban recursos para traer a estas ni costearse lujosos trajes y máscaras traídas a pedido desde Bolivia para rendirle culto a la virgen o a la Pachamama. Hoy a sus costosas y atractivas máscaras de diablos, deberían agregarle una mascarilla contra el COVID19.

\section{1) El turismo de memoria}

Hechos luctuosos, hechos dolorosos, procesos para no olvidar han sido recogidos en todo el mundo para que nunca más se olviden. Por eso, memoriales de derechos humanos, museos de la memoria, sitios donde ocurrieron matanzas y también hechos bellos e inolvidables se tornaron parte del circuito de este tipo de turismo a nivel educacional, local, regional, nacional e internacional. Tesis académicas de todos los grados se han escrito sobre la Memoria, luego estos hechos han sido recogidos por el turismo para mantenerlos vivos.

12) El turismo de observación

Una gran expresión del turismo con respeto por la naturaleza lo constituyó la observación de la flora y la fauna. Seres humanos conscientes del valor de este tipo de turismo y del valor de los animales y la flora, diversos y llenos de vida, concentraban sus esfuerzos económicos, de tiempo y dedicación a recorrer el mundo observando, simplemente observando a otros seres vivos. 
Cadernos CERU, Série 2, Vol. 31, n. 1, jun. 2020

13) El turismo de salud

También en este ámbito el turismo fue creciendo enormemente en las últimas décadas, aunque no es reciente, pero si su masificación.

En América Latina y el Caribe hay muchos ejemplos. Los chamanes, verdaderos y para turistas; el baño de temazcal, esa hidroterapia prehispánica, que tiene un efecto similar a las aguas termales, ya que también estimula la relajación mental y desintoxicación, las ofertas y el turismo de salud que ofrecen no solo a personas indígenas, sino que también a no indígenas la Machi Mapuche, o el turismo de salud por medio del aprovechamiento de aguas termales en los Andes chilenos, tales como las termas de Pica, Mamiña, Enquelga, Chuzmiza, las que ya constituían una ruta de las aguas termales en la zona norte de Chile. Esas rutas se repetían a lo largo de todo el continente. Esto lo explicaron muy bien en el "Caso de la Ruta de la Salud de Michoacán" Georgina Arévalo Pacheco e Hilda Guerrero García. ${ }^{5}$

14) El turismo de ecología profunda

Sobre el turismo de ecología profunda y sus variables no se ha escrito mucho en una dimensión del turismo 4.0. post pandemia. En este ámbito se establece como una de las respuestas que el mundo del turismo hace mucho tiempo que debería haber introducido antes de la pandemia. Hoy estamos pagando las consecuencias. Nos encontramos enclaustrados y el turismo ha cesado. Sin embargo, es a través de este tipo de turismo que se podrá recuperar lo des-andado para poder echar las bases para una nueva relación entre los viajes, los viajeros, los visitantes y los visitados y naturalmente la Pachamama. Pero no solo en el turismo debe avanzar la ecología profunda como lo demuestra en su estudio Adriana Norma Martínez en su estudio Una nueva visión del mundo: la ecología profunda y su incipiente recepción en el derecho nacional e internacional (primera parte) ${ }^{6}$.

\section{Era de la post pandemia}

Sin embargo, en una época Post Pandemia deberíamos revisar los mismos conceptos.

1) Los viajes de nuevos descubrimientos

Deberán estar imbuidos de una nueva concepción de la visita y de la cultura del visitante. No se podrán realizar más descubrimientos a costa de los territorios visitados sin la anuencia de sus pueblos y sin el respeto hacia la naturaleza. De hecho se producirán nuevos tipos de descubrimientos compartidos.

\footnotetext{
${ }^{5}$ file:///C:/Users/Bernardo\%20Mu\%C3\%B1oz/Documents/Convenio\%20SUR-SUR/DialnetTurismoDeSaludPorMedioDelAprovechamientoDeAguasTer-5371172.pdf

${ }^{6}$ file:///C:/Users/Bernardo\%20Mu\%C3\%B1oz/Documents/Corfo_2019/Dialnet-UnaNuevaVisionDelMundo6203517.pdf
} 
2) Los viajes masivos

Estos nuevos viajes deberán contemplar diversas medidas destinadas a proteger al visitante, al visitado y a los destinos elegidos. Se establecerán todas las medidas que permitan que el visitante pueda elegir un destino sin dañar a este y con los respectivos códigos y protocolos tanto sanitarios como culturales.

3) Los viajes All inclusive

Indudablemente que serán los más difíciles de reestablecer, debido a la nueva situación de los espacios de confort a compartir, lo que deberán de ser redefinidos en todos sus aspectos. Dependerá además de la cultura del viajero. Si este viene de Europa, Norteamérica, Asia, Oceanía, América del Sur o si es un viaje interno es decir nacional. Los comportamientos serán los que establezcan los visitados más los protocolos que se generen en un ámbito durante la pandemia por parte de las organizaciones ligadas a la gobernanza del turismo, partiendo por la OMT.

\section{4) La sobrecarga de los cielos}

En estos momentos, las grandes flotas de aviones se encuentran en quiebra y en sus hangares, si se observa el mapa de vuelos en el espacio a través de mapas y fotos satelitales, los cielos y sus gozan de un gran descanso y se produce una gran descontaminación del aire producto de estos entretiempos. Una discusión que se deberá llevar a cabo, será el de la optimización y mejoramiento de las rutas en base a opciones sino más ecológicas, al menos más sustentables para mejorar el daño producido durante al menos 50 años de un uso perverso de los cielos y de la rentabilidad de las líneas aéreas para bienestar de sus pasajeros que nunca se preguntaron sobre el daño ocasionado. Su objetivo era llegar al destino de la forma más rápida no importando el costo económico ni el ecológico.

5) La sobrecarga de la Pachamama

Indudablemente que quien más se ha resentido con este proceso a escala inhumana ha sido la Pachamama. Hasta que habló, desde Machu Pichu, la Amazonia, desde los mares y playas convertidos en cloacas y desde sus desiertos convertidos en basureros. Hablaron sus parques naturales debido a los restos malagradecidos de las visitas irrespetuosas y estridentes. Hoy durante la pandemia la Amazonia ya no se quema, pero sus habitantes mueren contagiados por un nuevo virus extraño a sus propias patologías y que durante siglos los han diezmados.

6) Tres ejemplos de círculos virtuosos en el mundo a visitar en esta nueva era turística: Torres del Paine, Costa Rica y los circuitos de turismo indígena y vivencial de los indios Kuna de Panamá. 
1) Es el caso de Torres del Paine ${ }^{7}$ que indica que debe haber una política de Estado para generar un turismo sostenible para Chile, optimizando la gestión de sus atractivos turísticos. Y plantea una visión desde la óptica de la antropología, para el turismo cultural, el turismo con respeto, las buenas prácticas y la difusión de este a nivel de América Latina y el Caribe. Indica a la vez que todo destino en Chile puede ser un Torres del Paine si existe una buena gestión del destino, una visión de sostenibilidad, estándares internacionales, participación en su gestión de los actores locales en conjunto con instituciones altamente preparadas, nacionales y/o internacionales, pero por sobre todo con un alto concepto del turismo de ecología profunda.

2) Costa Rica es un país que en su gestión turística se ha distinguido por ser una reserva de la biosfera y ha establecido desde hace mucho tiempo estrictas normas de comportamiento a sus visitantes y a los operadores de su destino país.

3) En el caso de los indios Kuna de Panamá son entre los diversos grupos indígenas del continente que han desarrollado uno de los que más han implementado un modelo de gestión turística en su territorio, que al menos privilegia la siguiente triada: Potenciamiento de la sostenibilidad de su territorio, su cultura y por sobre todo una oferta basada en el respeto del visitante al pueblo visitado, a su cultura y a su territorio.

7) El turismo respetuoso

Seguirá siendo un turismo altamente relevante y por sobre todo creo que representará una suerte de constricción del ser humano viajero hacia aquello y aquellos que antes no vio ni respetó. Demandará de nosotros cuidar cada paso, cada palabra, cada acción que venga a romper la cadena de valor que se estableció antes de la pandemia y que en una situación Postpandemia deberá ser extremadamente estudiada y difundida entre los viajeros y los tours operadores, así como también por los organismos internacionales, desde la Organización Mundial del Turismo, OMT, hasta la más pequeña instancia receptora de viajeros en su destino. Es necesario de que se fortalezcan y creen nuevos códigos y normas entre los distintos stakeholders, internacionales, nacionales, regionales y locales, hasta llegar a un respeto mutuo e irreductible. A este tipo de turismo está muy ligado el ya mencionado turismo vivencial, de alto valor ya en tiempos anti pandemia. Deberá ser profundizado a partir de esta nueva realidad.

\footnotetext{
${ }^{7}$ Marca Chile: "TODO CHILE ES UN TORRES DEL PAINE" Estrategia metodológica desde las Ciencias Sociales y la Antropología para transformar a Chile en un Destino turístico sin brechas y como motor de desarrollo. Inscripción A304552 del Departamento Autoral de Chile.
} 
8) El turismo de voluntariado

Este tipo de turismo ya se había desarrollado durante los últimos 30 años aproximadamente, sin embargo, en una etapa post pandemia, se espera que estos voluntarios crezcan por miles, imbuidos de su convicción de que la vida les ha dado una nueva oportunidad para acudir a ejercer sus labores en pro de los visitantes, los territorios visitados, en la educación de los viajeros en el destino elegido y por sobre todo en el cuidado de la Pachamama.

9) El turismo sexual

Si bien es cierto se piensa que este continuará su lúgubre existencia y no sólo en la América hispano hablante, sino que también en el luso hablante, es de esperar que tanto los señores y señoras turistas, en una fase de post pandemia, piensen que la Pachamama les ha dado una nueva oportunidad de un nuevo tipo de viaje, lo que incida en una menor explotación sexual de hombres y mujeres de nuestro continente.

Para el turismo gay o gay friendly, los destinos en América Latina y el Caribe, debiera generarse una reflexión similar, ya que, en muchos casos, ocurre algo parecido, pero sin embargo también existen ofertas muy atractivas para parejas homosexuales y lésbicas.

10) El turismo interno

En esta nueva era para el turismo, se espera que sea el turismo interno el que en primer lugar se reposicione, así como al parecer lo será en el verano europeo para lo cual se están creando todos los protocolos necesarios para que en julio y agosto del 2020 se produzca en forma ordenada, con estrictos códigos sanitarios y de estadías responsables para ese continente.

11) El turismo virtual

De cualquier forma, después de esta pandemia emergerá un nuevo turismo, el virtual. Ya antes de la pandemia se venían tridimenzionalizando los destinos, toda vez que los viajeros de Europa, Asia, Oceanía, Canadá y EEUU, principalmente, preparan con mucha antelación sus viajes. Por lo tanto, se informaban sobre todos los aspectos del destino a visitar. Por esto se comenzó a poner en una dimensión virtual, museos, iglesias, patrimonios culturales materiales e inmateriales, de tal forma que el turista pudiera ya experimentar desde casa, en grupo o individualmente, lo ofrecido por ese lugar, antes de comprar sus boletos de avión, reservar hoteles y dar inicio al viaje. En esta nueva dimensión post pandemia y a través del turismo virtual se pueden seguir desarrollando los siete siguientes tipos de visitas:

1) El turismo ecológico

Sin dudas que será un bien preciado para recomenzar a plantear una nueva educación para y con la Pachamama. Desde su más tierna infancia todos los componentes humanos, educativos y de la cadena del turismo sostenible deberán dar el mayor énfasis en ésta área del 
Cadernos CERU, Série 2, Vol. 31, n. 1, jun. 2020

turismo. Es impostergable. Por lo tanto, se debería incluir en las asignaturas desde la escuela básica en torno a cómo cuidar los espacios que voy a visitar para que así estos puedan seguir siendo visitados con sostenibilidad inagotable.

2) El turismo religioso

Indudablemente que este tipo de turismo deberá ser completamente reestructurado y reorientado a una categoría virtual sin aglomeraciones, destacando la importancia del sincretismo religioso propio de los Andes.

3) El turismo de memoria

Hay sin dudas una deuda con la Pachamama. Esta debe ser saldada no sólo con los grupos sociales y culturales que la habitan en los sitios que constituyeron hechos, sino que la Pachamama como un todo incumbente, debería ser sujeta de Memoria. Se deberá establecer el hito de que a partir de la nueva era post pandemia no solo los sitios históricos deberán ser respetados, sino que con mayor razón aún su principal continente. Nuestra Pachamama.

4) El turismo social

Ya antes de la pandemia el turismo social se había transformado en una gran variable para muchos viajeros que ya venían de vuelta de los viajes de resorts y de los viajes en transatlánticos, que hoy se llaman los transatlánticos del contagio y que pudieron advertir que una opción muy interesante para sus vidas de viajeros era el viajar para compartir un día de sus vidas con el cotidiano de personas que tenían un estándar de vida, tanto social, como económico, así como cultural en muchos países del mundo. Hoy se deberá esperar para establecer los nuevos protocolos para desarrollar con más fuerza aun lo que nos demostrará que todas nuestras diferencias cualitativas y cuantitativas fueron ignoradas por esta pandemia. Vendrá por lo tanto un gran proceso de educación en el que el turismo podrá desempeñar un gran rol neo civilizador.

5) El turismo de observación

Este tipo de turismo será sin dudas privilegiado, y no solamente en términos presenciales, sino que también virtuales, ya que el acercarse desde otra dimensión nuevamente a los seres vivos que no fueron ni siquiera tocados ni siquiera por la pandemia del COVID19, nos demostrará nuevamente, lo débiles que somos los seres humanos. He ahí un cambio hacia la ecología profunda y que evidentemente tendrá un desarrollo invaluable para un nuevo turismo 4.0 .

6) El turismo de salud

Este será un gran tipo de turismo en primer lugar de orden interno y luego podrá abrirse a los amantes de este tipo de turismo. Debiera privilegiarse aquellos que no atenten contra la 
Cadernos CERU, Série 2, Vol. 31, n. 1, jun. 2020

naturaleza y primordialmente que se recurra a las verdaderas fuentes de conocimiento ancestral no dando espacio para aquellos montajes para el turista que sólo buscaban réditos económicos en base al usufructo de un conocimiento ancestral. Sería un gran proceso de re-educación para la salud física, mental y en la relación con la Pachamama.

7) El turismo de ecología profunda

Todos estos tipos de turismos antes enunciados deberán compartir y valorar enormemente al turismo de ecología profunda que será la única posibilidad de llegar al turismo 4.0, de suyo la variable más relevante de esta nueva era.

Será el nuevo territorio no solamente físico, sino también cultural de encuentro de los seres humanos viajeros y gestores del destino para llegar justamente a ese turismo 4.0 que engloba a todas las anteriores formas de encuentro de una nueva manera, a escala humana profunda y respetuosa de los equilibrios en todos los ámbitos.

\section{Conclusiones}

En el caso chileno, en estos momentos de pandemia, cuando se habla de cifras y sólo cifras, el gremio turístico estima pérdidas por 330 millones de dólares en el fin de semana santa, primer fin de semana largo del año de abril del 2020.

La crisis que está enfrentando el país por el Coronavirus, ha llevado prácticamente a niveles cero la actividad turística durante los distintos feriados largos existentes en él, profundizando el impacto negativo que está provocando la pandemia en el sector.

En esta oportunidad el escenario fue completamente distinto, por la pandemia que afecta al país y que ha llevado a las autoridades sanitarias a disponer de medidas para frenar la propagación del Covid-19, entre ellas, la implementación de cordones sanitarios y el fuerte llamado de las autoridades para que aquel fin de semana largo, las personas se queden en sus casas y no se trasladen hacia la costa u otros puntos turísticos.

Medidas a las que adhiere la industria del turismo, pero que sin duda representan un fuerte impacto para el sector. De acuerdo a datos entregados por Fedetur, en el feriado largo de Semana Santa de 2019, se realizaron un poco más de 3 millones de viajes (3.046.186 viajes) con pernoctación a lo largo de todo Chile.

Esa cifra fue un 3,2\% mayor que los viajes con pernoctación realizados en el mismo período de 2018. En tanto, para 2020, se estimaba que esta cifra se podría haber incrementado un 2\%, llegando a 3,1 millones de viajes con pernoctación. Sin embargo, las restricciones de desplazamiento, llevarán esa estimación a cero.

Considerando que el gasto promedio diario individual, en este tipo de viajes, es de $\$ 31.000$, y contemplando una pernoctación de 3 noches, la pérdida estimada para el sector es 
de US\$330 millones, este fin de semana largo. Monto que incluye la pérdida por gastos no realizados por los turistas en los destinos a los cuáles se habrían desplazado.

Las regiones más visitadas en estos viajes durante Semana Santa, son la Región de Valparaíso, con un 25,9\% de los viajes, seguida de la región de Bio Bío, con un 12,4\%. En tercera posición se ubica la Región de O’Higgins con un 11,9\%, y luego la Región Metropolitana con un 10,6\%. Estas cuatro regiones se encuentran con cordones sanitarios precisamente para evitar el desplazamiento de personas, como parte de las medidas para enfrentar el Coronavirus.

El presidente de Fedetur, Ricardo Margulis, afirmó que "en medio de esta pandemia, lo que está primero es la vida y la salud de las personas", y por lo mismo, hizo un llamado a respetar la determinación de las autoridades a quedarse en casa este fin de semana largo.

Entendemos que estamos frente a una emergencia sanitaria y hay que tomar conciencia de los riesgos a los que nos exponemos si no respetamos la cuarenta impuesta por las autoridades. No obstante, como sector, esta restricción de desplazamiento nos golpea fuerte, considerando que es una fecha muy sensible, ya que son muchos los chilenos que aprovechan este feriado para recorrer el país y hacer turismo, y que ahora no lo harán, puntualizó el representante de Fedetur.

Margulis reiteró la necesidad de que se pongan en marcha lo antes posibles las medidas que vayan en ayuda de la actividad turística, con el propósito de inyectar liquidez a las empresas del sector para que se mantengan en pie y se pueda proteger el empleo. En este sentido, el representante gremial valoró las medidas económicas anunciadas ayer por el gobierno. “ $L a$ creación de un fondo de garantía estatal para que los bancos puedan otorgar líneas de crédito de capital de trabajo a las empresas con ventas de hasta 1 millón de UF, es positiva, y va en la línea de lo que hemos estado pidiendo como sector", concluyó.

En tanto en Europa, ya se piensa en abrir algunos destinos con todos los protocolos necesarios. En Francia, Córcega quiere exigir un test reciente de la COVID19 a quienes vayan a viajar a esta isla francesa. En el caso de que una persona esté infectada, habrá un seguro que se hará cargo de los costes de cancelación del vuelo o del pasaje del ferry, así como de la reserva de alojamiento.

El presidente del Consejo Ejecutivo corso, el nacionalista Gilles Simeoni, defendió la iniciativa en una entrevista, ayer, con el diario Le Parisien. La exigencia del test negativo de la Covid-19 será para todos, sin excepciones: los turistas, franceses o extranjeros, los corsos “de la diáspora" o los habitantes de la isla que han pasado unos días en el continente o en otro país.

Simeoni reconoció que un test efectuado tres o cuatro días antes del viaje no es una garantía total, aunque sí da más seguridad de que no se vuelve a importar el coronavirus, sobre todo porque estará asociado a otras medidas de barrera y de higiene. Los líderes corsos piensan 
Cadernos CERU, Série 2, Vol. 31, n. 1, jun. 2020

que es importante el mecanismo de vincular automáticamente la reserva con un seguro que se hace cargo del coste de la anulación.

En comunicación escrita del 5 de mayo del presente año, Jordi Tresserras Juan, se refiere a lo que ocurre en las Islas Canarias, Baleares o ahora Córcega. Informa que la sugerencia es que antes de embarcar se deberá tomar la temperatura y realizar test rápidos (antígenos) o bien llevar por parte del viajero análisis realizados de la misma semana con test rápido (antígenos) que puede ser negativo o positivo (de haberlo pasado) y PCR negativo (que no se tiene o que se ha pasado). Agrega que al menos las mismas medidas son las que se aplican cuando una persona entra a quirófano.

En tanto el día 10 de mayo recién pasado en CNN Chile, la Presidenta y CEO del Consejo Mundial de viajes y turismo, dijo que se perderían 100 millones de puestos de trabajo en el turismo y que gran parte del turismo en el futuro será de forma virtual.

De la misma forma se remite al protocolo que menciona Jordi Tresserras Juan, respecto de los antígenos antes del viaje, ya que manifiesta, el 95\% de los viajeros no están contagiados. Por lo tanto, se privilegiarán los viajes domésticos o de índole nacional. La misma CEO prevé que una eventual normalidad será el año 2021.

Antes de la pandemia preparábamos una ponencia con la discusión entre el Turismo sostenible o turismo sustentable. Esto iba a ser en mayo del presente año, sin embargo, ya está previsto para septiembre. Si la Pachamama así lo quiere.

Esta ponencia preveía dialogar sobre el turismo, cultura y patrimonio natural, cultural, tangible, intangible, material e inmaterial. Sobre la industria del turismo desde la Organización Mundial de Turismo, OMT. Acerca de las principales diferencias entre el turismo sostenible y el turismo sustentable, ya que esta no es solo una cuestión de idioma: el término sostenible no existe en el idioma portugués, sin embargo, existe la palabra sustentável, que entiende el turismo sostenible como uno de carácter sustentable. Y aquí hay una diferencia considerable.

Nos interesaba dialogar sobre el turismo Naranja, que ha formulado el Dr. Jordi Tresserras Juan y que engloba al turismo vivencial, al turismo para pueblos originarios. Turismo y etnodesarrollo. Sobre el Turismo social y de Memoria, el turismo como factor de desarrollo para el territorio de los visitados, sobre el impacto negativo del turismo. Poner el ejemplo de la sexta invasión que ha ocurrido en el caso atacameño. Sobre el concepto de la sobrecarga turística y el colapso de un destino turístico, sumando a esto un turismo con identidad y calidad y con estándares internacionales, explicando la importancia del concepto de la interpretación en el turismo para poner en valor el patrimonio cultural, natural, material e inmaterial de los 
Cadernos CERU, Série 2, Vol. 31, n. 1, jun. 2020

pueblos indígenas, de cómo a través del turismo sostenible se propicia la creación de circuitos virtuosos para el turismo vivencial.

Y naturalmente sobre el futuro del turismo. ¿Son entonces hoy los no lugares de Marc Augé los actuales lugares? ¿Cómo se unía o relacionaba la realidad social y cultural versus la realidad virtual?

Bueno, todo eso ha quedado postergado en principio para el mes de septiembre de este año. Si es que la pandemia así lo permite.

Dentro del trabajo que se realizaba aquí en Chile, Corfo había generado un grupo de núcleos territoriales de gestión en el destino Programa territorial integrado. ${ }^{8}$

Se buscaba trabajar de manera unida para posicionar la marca de un territorio, lo cual según esta institución no es tarea fácil. Más aún cuando esto exige innovar, articular y planificar estratégicamente una zona, considerando sus atributos y valores. Uno de estos núcleos estaba implementado en la Región de la Araucanía y en esa instancia se encuentran representantes de las cámaras de turismo y empresarios de la Araucanía Andina, que reúne a las comunas de Curacautín, Lonquimay, Vilcún, Melipeuco y Cunco, con alto potencial turístico y que destaca por sus volcanes, lagos, montañas y multiculturalidad.

Con esta mirada se reunió en Cunco el directorio del Programa Territorial Integrado (PTI) de turismo de intereses, naturaleza y cultura, ejecutado por el agente operador Copeval y cofinanciado por Corfo, instancia donde participaron empresarios y municipios. El objetivo, avanzar en los lineamientos para potenciar un destino turístico con un modelo de gestión inteligente, reconocido a nivel nacional e internacional. Lo anterior, en base a la oferta de experiencias de turismo sostenible, de montaña todo el año, naturaleza, aventura, deporte, nieve y cultura mapuche. La ambiciosa iniciativa turística va en su primer año de ejecución y responde con creces al eje del Plan Impulso, orientado al turismo.

¿Cuál es la idea de estos núcleos territoriales locales según CORFO? El que se puedan superar las brechas existentes desde el propio territorio y a partir de los actores locales. Queda esperar que ocurrirá con este tipo de relevantes iniciativas una vez que escampe la pandemia.

\section{Hagamos de una primera crisis una oportunidad. La crisis social}

En un país convulsionado por los hechos acaecidos durante octubre del 2019 hasta febrero del 2020 las demandas sociales generaron una primera crisis al mundo turístico, con un alto impacto en el ámbito de la industria turística del país, y que puso definitivamente en entredicho su calidad de destino seguro y la Marca Chile, puesta en valor tras largos años de

\footnotetext{
${ }^{8}$ file:///C:/Users/Bernardo\%20Mu\%C3\%B1oz/Documents/Convenio\%20SUR-SUR/C.Extensionismo2017+-
} Anexo+Programas+Estrat\%C3\%A9gicos.pdf 
Cadernos CERU, Série 2, Vol. 31, n. 1, jun. 2020

trabajo y superación de brechas que pusieron al país como un destino privilegiado para el turismo internacional, principalmente norteamericano, europeo, asiático y sudamericano, este último segmento representado fundamentalmente por los turistas brasileños, con un alto gasto diario, pasando por ejemplo de ser Santiago una de las capitales más seguras del continente a ser una ciudad no recomendada para visitar.

\section{Pérdidas económicas hasta antes de la pandemia del COVID19}

Sólo con la cancelación de las Cumbres de la APEC y la COP25 las pérdidas estimadas por la visita de cerca de 27.000 personas se calculó en un mínimo aproximado de US\$ 30 millones.

Pasadas unas nueve semanas de los hechos por todos conocidos, se pudo calcular que el costo de pérdidas por los mismos hechos, cancelaciones, menos visitantes, daño a la propiedad privada en el área del turismo, como así también con la disminución de los precios de las ofertas hoteleras, gastronómicas y de turismo indoor y outdoor, sistemas de tour incluidos en los paquetes turísticos, llegaron a los US\$ 300 millones. Sin pandemia se calculaba hasta fines del año pasado, en donde las principales ciudades del país no realizaron las tradicionales celebraciones de fin de año con fiestas asociadas al borde costero y fuegos artificiales, en donde las ofertas turísticas asumen una gran demanda hotelera, gastronómica y de ocio que incide fuertemente en la economía nacional desde el área del turismo, se pudo alcanzar una cifra aproximada de US\$ 2.000 millones en pérdidas económicas del sector.

En esa misma fase, los precios de los hoteles del centro de Santiago en la modalidad de reserva normal, se encontraron con sus precios bajo o cerca de los $\$ 50$ mil pesos por noche para dos personas, con baño privado y desayuno incluido, más una serie de otras ofertas para captar un público escaso, como es el caso del Park Plaza Apart Hotel con un precio de \$46.600, lo que incluía desayuno. Este era el caso de decena de hoteles, hostales y Apart Hoteles del centro de Santiago, donde había gran disponibilidad de reservas y evidentemente falta de demanda. Hoy están completamente vacíos y con quiebras económicas por doquier.

En esa misma época propusimos a la Subsecretaría de Turismo a través del Convenio SUR-SUR, una estrategia para actuar en la anterior situación de crisis. A saber:

\section{Descongestionar}

Ante las evidentes brechas de seguridad existentes, principalmente en la Regiones Metropolitana y de Valparaíso, principales ciudades de atracción turística en el centro de Chile y donde se necesitaría un mayor tiempo de inversión en la recuperación del patrimonio dañado y de las ofertas receptivas de hoteles, hoteles boutique, hostales, ofertas gastronómicas: todos estos de pequeño y mediano tamaño fundamentalmente, no observándose un efecto mayor en 
las grandes cadenas en materia de daños, pero si en el número de reservaciones y también en el contrato de tours por dichas ciudades y sus entornos. Hoy la inseguridad está al 100 por ciento y no hay autorización para visitantes en el país.

\section{Hacia donde descongestionar}

Evidentemente Chile cuenta con otros destinos tanto continentales como insulares, a lo largo y ancho del país.

La pregunta es si estos destinos estaban preparados para recibir una sobredemanda sustantiva, a lo cual hace mención el documento: "Marca Chile: "TODO CHILE ES UN TORRES DEL PAINE" Estrategia metodológica desde las Ciencias Sociales y la Antropología para transformar a Chile en un Destino turístico sin brechas y como motor de desarrollo"9.

Indudablemente que todo parte por una buena gestión del destino turístico, el que debe contar con una buena planta turística acorde a atractivos con estándares internacionales con identidad y calidad y ahora con los respectivos protocolos ya mencionados para una fase Postpandemia.

Ya ese documento se planteaba que en aquellas instancias se debería privilegiar el Turismo cultural, vivencial y ecológico profundo como lo es la actividad de observación de ballenas, santuarios de la naturaleza, Parques Nacionales y áreas protegidas, las rutas gastronómicas y del vino, entre otras como los territorios existentes en el sur de Chile, donde se encuentran muchas áreas descongestionadas con propuestas de ecología profunda y turismo étnico, vivenciar el sitio, turismo vivencial, la espiritualidad y ritualidad en el destino, en los cuales estos últimos rubros se han especializado tanto las ofertas de cómodos resorts y SPA así como también comunidades indígenas tanto en el norte como en el sur del país. Esto naturalmente se debe revisar a la luz de los actuales acontecimientos.

Lo mismo ocurre con las propuestas de Rapanui y la Isla Juan Fernández, quienes por sí representan un destino único a nivel nacional e internacional.

Esta propuesta hecha en aquel entonces se mantiene vigente tomando todas las providencias de la nueva era, ya que sería inaudito plantear en estas especiales instancias que se generasen iniciativas específicas para el Chile continental.

\section{Recuperación del Destino Chile Central (Regiones de Metropolitana y Valparaíso)}

En aquella contingencia se habría necesitado de un periodo de 6 meses a un año, habiendo puesto en riesgo la pasada temporada estival y de la próxima temporada de invierno 2020. Ahora se debería preparar el escenario para el verano del año 2022.

\footnotetext{
${ }^{9}$ Dr. Bernardo Muñoz Aguilar et alii, 2019.
} 
Cadernos CERU, Série 2, Vol. 31, n. 1, jun. 2020

\section{Objetivo ex ante de la pandemia}

Reposicionar la marca del destino Chile y sus atractivos turísticos como un destino seguro con estándares comprobados de calidad e identidad.

Se debería haber trabajado arduamente durante un año al menos para redireccionar las ofertas en el corto, mediano y largo plazo, con una estrategia comunicacional internacional del discurso sobre lo que ocurre en Chile por parte de los operadores turísticos. Ahora se debe generar una estrategia para replantearse el DESTINO CHILE como un destino libre de COVID19.

\section{Público objectivo}

La propuesta de reposición de la MARCA CHILE debe ser dirigida a dos públicos: Se pensaba que se le debía proponer al turista chileno el que visitase Chile y no se fuese al extranjero, generando más deuda para un público ya de por sí altamente endeudado pero que prefiere vacacionar en otro país por el riesgo existente en el imaginario del turista que hay hoy en Chile. No sólo descansar, sino que buscar alejarse del estrés que les ha producido la situación nacional para su necesaria búsqueda de ocio y relajo. Por lo tanto, se debían generar dos estrategias diferentes, cada una entre sí, tanto para el turista chileno como para un público extranjero. Hoy se debe trabajar por generar nuevamente un turismo interno pensado recién en el verano del año 2021.

\section{Que había que hacer}

Además de la necesidad de revisar la estrategia nacional de turismo 2020-2030, la cual con las pasadas circunstancias evidentemente iban a evidenciar diversas brechas en su propuesta, las que deberían haber sido homologadas con la situación ex post 19 de octubre del año 2019. Sin embargo, dicha estrategia, producto de la primera crisis, es decir la social, no alcanzó a ser publicada y ahora con la segunda crisis deberá ver la luz a fines quizás de este año, cuando se alcanzasen a evidenciar los reales impactos en la industria producto de esta segunda crisis.

\section{El caso de Rapanui post pandemia}

Rapanui es considerado un destino único, como lo es el caso de las Islas Maldivas, Río de Janeiro, Machu Pichu, Torres del Paine, entre otros. Sin embargo, en una situación Postpandemia, esta calidad de destino único deberá ser revisada en relación a que se va a entender como un destino único a partir de los términos de la cuarentena en los respectivos destinos. 
Según el experto del Convenio SUR-SUR, el Dr. Jordi Tresserras Juan, recogiendo informaciones vertidas por Núria Vila, desde Malmö, Suecia, al diario La Vanguardia. Según la publicación, una buena medida para reactivar el tránsito turístico lo pretende implementar Islandia, país que aceptará turistas a partir del 15 de junio del presente año con un simple test y sin cuarentena. El turismo es la primera actividad económica de la isla, y el 23\% de los que la visitan procede de EE.UU.

En un intento de salvar la temporada turística, el Gobierno de Islandia ha decidido abrir sus fronteras a partir del 15 de junio y permitir la entrada de todos los viajeros, también los que procedan de fuera de la Unión Europea. Para garantizar que están libres del virus deberán mostrar un certificado válido o hacerse un test de detección al llegar al aeropuerto, y si el resultado es negativo, podrán ahorrarse las dos semanas de cuarentena ahora obligatorias.

Queda por determinar quién asumirá el coste de los test, ya que el Gobierno no ha concretado si el dinero saldrá de las finanzas públicas o de los bolsillos de los propios viajeros. Además de la prueba a la llegada, las autoridades han avanzado que probablemente requerirán descargar y utilizar la aplicación oficial de rastreo del virus, que ya usa el 40\% de la población y que ayuda a contener su propagación cuando se detectan nuevos contagios.

La estrategia de Islandia de test a gran escala, rastreo y aislamiento ha sido efectiva hasta ahora, y queremos basarnos en esto para crear un lugar seguro para quienes quieran un cambio de escenario después de una primavera difícil para todos, argumentó la ministra de Turismo, Thordis Kolbrun Reykfjord Gylfadottir.

Gracias a la colaboración con la empresa privada de Code Genetics, Islandia (364.000 habitantes) ha testeado a un $16 \%$ de su población, poniendo en cuarentena a todos los contagiados y a sus contactos, lo que ha contribuido a frenar la cadena de transmisión. En mayo sólo se han detectado cuatro nuevos casos.

Desde el 20 de marzo, los extranjeros no europeos tienen prohibida la entrada a Islandia -excepto si demuestran un motivo de fuerza mayor-, una restricción que afecta a su principal mercado emisor, Estados Unidos, de donde procedió más del 23\% de los dos millones de turistas que llegaron el año pasado. El Gobierno se da un mes de margen para garantizar que tiene test para todos los visitantes, aunque a partir de este viernes ya relajará las restricciones de entrada para ciertos colectivos, como científicos, deportistas y productores de audiovisuales. "Va a ser un proyecto un poco experimental”, dijo la primera ministra, Katrín Jakobsdóttir, en una entrevista en la CNN, ya que admitió que será una temporada turística mucho más floja.

Obviamente, no esperamos dos millones de visitantes este año, afirmó, aunque añadió que la intención con esta estrategia de test masivos es facilitar los viajes a la isla. El Gobierno ha invertido 9,5 millones de euros en una campaña promocional bajo el lema "Islandia, adelante juntos. 
El sector turístico, que aporta alrededor de un 9\% del PIB, ha recibido con satisfacción el anuncio de la apertura de fronteras, aunque queda una gran incertidumbre: la viabilidad de Icelandair, la mayor aerolínea del país. La epidemia ha hundido a la compañía en una crisis que podría acabar en una quiebra. "Todo depende de que Icelandair continúe operando, y realmente es una cuestión de vida o muerte para el turismo en Islandia", afirmó la directora de la asociación islandesa del sector turístico, Bjarnheidur Hallsdóttir, al medio local The Reykjavík Grapevine. El Gobierno ha afirmado que está preparado para ofrecer garantías de crédito a la aerolínea, pero también ha avisado de que no tiene intención de intervenir para rescatarla.

Esto puede tener relación directa con una posible estrategia para Rapanui, al implementar medidas similares, pero además aprovechando una ruta por vía aérea transoceánica vía Papeete, en Tahití, ruta la cual ha sido usada milenariamente ya por los antiguos navegantes melanesios.

Cabe consignar, además, que, con esta segunda crisis, a las sumas económicas ya expuestas, con el cierre de las fronteras para el turismo se ha ocasionado para el capital humano de la industria, la pérdida de al menos 100.000 empleos. Estos no son solo cifras, son los costos humanos que ha traído entre otros la actual pandemia.

\section{Nuevos rituales en relación a los territorios y el turismo}

A partir de los que dice el filósofo alemán Byung-Chul Han, nacido en Corea del Sur y que expresa en su libro "La desaparición de los rituales", aparece la idea de la necesidad de crear nuevos rituales, toda vez que los anteriores ha sido separados. Entre otras aseveraciones el mencionado autor dice que la desaparición de los rituales señala sobre todo que, en la actualidad, la comunidad está desapareciendo.

Esto principalmente a partir de la hipercomunicación consecuencia de la digitalización, que nos permite estar cada vez más interconectados, pero esta interconexión no trae consigo más vinculación ni más cercanía. Las redes sociales también acaban con la dimensión social al poner el ego en el centro.

A pesar de la hipercomunicación digital, en nuestra sociedad la soledad y el aislamiento aumentan. Hoy se nos invita continuamente a comunicar nuestras opiniones, necesidades, deseos o preferencias, incluso a que contemos nuestra vida. Cada uno se produce y se representa a sí mismo.

Todo el mundo practica el culto, la adoración del yo. Por eso digo que los rituales producen una comunidad sin comunicación. En cambio, hoy prevalece la comunicación sin comunidad. Cada vez celebramos menos fiestas comunitarias. Cada uno se celebra solo a sí mismo. Deberíamos liberarnos de la idea de que el origen de todo placer es un deseo satisfecho.

Solo la sociedad de consumo se orienta a la satisfacción de deseos. Las fiestas no tienen que ver con el deseo individual. En el juego colectivo uno no procura satisfacer su propio deseo. Antes bien, se entrega a la pasión por las reglas. No estoy diciendo que tengamos que volver al pasado. Al contrario. Sostengo 
que tenemos que inventar nuevas formas de acción y juego colectivo que se realicen más allá del ego, el deseo y el consumo, y creen comunidad.

Plantea que se ha olvidado que la comunidad es fuente de felicidad.

La libertad también la definimos desde un punto de vista individual. Freiheit, la palabra alemana para "libertad", significa en origen "estar con amigos". "Libertad" y "amigo" tienen una etimología común. La libertad es la manifestación de una relación plena. Por tanto, también deberíamos redefinir la libertad a partir de la comunidad.

\section{El turismo desde la Antropología social}

La antropología social como ciencia es una observadora privilegiada del comportamiento humano, de sus culturas y de su devenir. Es desde esta óptica que aquí se aborda el turismo, el turismo sostenible y la necesaria ecología profunda en su accionar futuro. Usa la historia como una ciencia auxiliar para evidenciar y proponer futuros logros para la humanidad. En este caso concreto nos ocupamos desde la antropología hacia el turismo y sus actores, los territorios, los viajeros y los visitados para sugerir nuevos alcances que optimicen su accionar. Serán estos actores y también los antropólogos y antropólogas los que deberán marcas las nuevas rutas a recorrer juntos con la Pachamama.

¡Esto es una gran revolución! Y tenemos la posibilidad de ser parte de ella, para de alguna forma incidir en la enseñanza del turismo sostenible y de ecología profunda.

\section{Bibliografía}

RESTREPO, Pedro Felipe Buitrago; MÁRQUEZ, Iván Duque. (2013). “La Economía Naranja. Una oportunidad infinita". Colombia.

CORFO. Priorización de programas estratégicos llamados centros de extensionismo tecnológico. (2017).

file:///C:/Users/Bernardo\%20Mu\%C3\%B1oz/Documents/Corfo_2019/DialnetUnaNuevaVisionDelMundo-6203517.pdf

MUÑOZ, Bernardo. (2019). Marca Chile: "TODO CHILE ES UN TORRES DEL PAINE" Estrategia metodológica desde las Ciencias Sociales y la Antropología para transformar a Chile en un Destino turístico sin brechas y como motor de desarrollo. Inscripción A304552 del Departamento Autoral de Chile.

MUÑOZ, Bernardo. (2015). Desde la antropología al turismo sostenible. El patrimonio cultural indígena de Tarapacá como Destino turístico. Identidad e Innovación. VII Congreso de la Sociedad de Investigadores de Turismo, En: El turismo y su relación con la comunidad local, el desafío de la sustentabilidad: experiencias de investigación, desarrollo e innovación. Anales del VIII Congreso de la Sociedad de Investigadores en Turismo. Santiago de Chile. Publicación indexada.

MUÑOZ, Bernardo. (2013). "Relaciones entre Chile, Perú y Bolivia desde la óptica de Tarapacá, en la actualidad". Actas del 8vo. Congreso nacional de Antropología. Arica, noviembre de 2013. Publicación indexada. 
MUÑOZ, Bernardo. (2013) Desde la antropología al turismo sostenible. El patrimonio cultural indígena de Tarapacá como Destino turístico. Identidad e Innovación. Actas del 8vo. Congreso nacional de Antropología. Arica, noviembre de 2013. Publicación indexada.

MUÑOZ, Bernardo. (2012). Desde la etnografía antropológica hacia un turismo sostenible. 1er. Congreso Iberoamericano de Patrimonio turístico, Universidad Central. Publicación Indexada. Instituto del Patrimonio, Universidad Central.

MUÑOZ, Bernardo. (2017). "Desde la etnografía antropológica hacia un turismo sostenible. Una metodología de abordaje teórico- práctica. El caso de la Macrozona andina norte, en las actuales regiones de Arica-Parinacota, Tarapacá y en Chile”. São Paulo: Centro de Estudos Rurais e Urbanos, CERU, Universidad de São Paulo.

https://www.revistas.usp.br/ceru/article/view/137124

MARTÍNEZ, Adriana Norma. Data? Una nueva visión del mundo: la ecología profunda y su incipiente recepción en el derecho nacional e internacional (primera parte)".

PACHECO, Georgina Arévalo; ROJAS, Hilda Guerrero García. (2014). El Caso de la Ruta de la Salud de Michoacán.

file:///C:/Users/Bernardo\%20Mu\%C3\%B1oz/Documents/Convenio\%20SUR-SUR/DialnetTurismoDeSaludPorMedioDelAprovechamientoDeAguasTer-5371172.pdf

BALLART, Josep / Juan Tresserras, Jordi. Gestión del patrimonio cultural.

https://www.todostuslibros.com/autor/tresserras-juan-jordi

GUTIÉRREZ, Jordi Gascón; PÉREZ, Soledad Morales; JUAN, Jord Tresserras. Cooperación en turismo.

https://www.todostuslibros.com/autor/tresserras-juan-jordi

BYUNG-CHUL, Han. (2020). La desaparición de los rituales. Herder. 